\title{
EFFECT OF SILVER NANOPARTICLE-MEDIATED WOUND THERAPY ON BIOCHEMICAL, HEMATOLOGICAL, AND HISTOLOGICAL PARAMETERS
}

\author{
PALLAVI SINGH CHAUHAN ${ }^{1}$, VIKAS SHRIVASTAVA ${ }^{1 *}$, PRASAD GBKS ${ }^{2}$, RAJESH SINGH TOMAR ${ }^{1 *}$ \\ ${ }^{1}$ Department of Amity Institute of Biotechnology, Amity University, Gwalior - 474 005, Madhya Pradesh, India. ${ }^{2}$ Department of S.0.S. \\ Biochemistry, Jiwaji University, Gwalior - 474 011, Madhya Pradesh, India. Email: rstomar@amity.edu/vshrivastava@gwa.amity.edu
}

Received: 08 November 2017, Revised and Accepted: 07 December 2017

\section{ABSTRACT}

Objective: Green synthesis of nanoparticles has been used as an alternative, efficient, less expensive, and ecofriendly method. Ancient approaches employed for nanoparticle fabrication were chemical and physical methods having various disadvantages as they are costly and potentially harmful to the environment, use of harsh chemicals and stringent protocol for synthesizing nanoparticles. The present study is focused on the synthesis of silver nanoparticles by bio-availed as well as chemical route and evaluation of their wound healing potential in Wistar rat model.

Methods: Extraction of Syzygium cumini was done and was used for silver nanoparticle synthesis. The synthesized nanoparticles were characterized by ultraviolet-visible spectroscopy, Fourier transform infrared spectroscopy, scanning electron microscopy, and transmission electron microscopy, which confirms the availability of nanosilver particles with marginally spherical morphology. The particles were then carried forward for treating impaired diabetic wounds in Wistar rat models. Regular photography was done and wound healing parameters were monitored throughout the study along with analyzing other parameters such as biochemical, hematological, and histological parameters.

Results: The study showed that the sizes of the synthesized nanoparticles are below $100 \mathrm{~nm}$. The results obtained from in vivo studies showed efficient wound healing potential of silver nanoparticles as compared to pre-existing drug povidone-iodine, i.e., the percentage reduction in wound area after therapy is $96.09 \%$ in case of biosynthesized silver nanoparticle-treated group, $97.7 \%$ reduction in chemically synthesized silver nanoparticle-treated group, 64.28\% reduction in case of pre-existing drug povidone-iodine-treated group, 37.5\% reduction in case of diabetic control group (diabetic), and $97.5 \%$ reduction in normal control group (non-diabetic). Results showed that biosynthesized silver nanoparticles showed less toxicity with respect to liver and kidney functions. Skin histology results showed increased sign of wound healing in biosynthesized silver nanoparticles. Hematology results showed no such variation.

Conclusion: The study will help to synthesize new economically viable potential biosynthesized nanoparticles along with providing the approach to develop the medication at nanoscale level.

Keywords: Nanoparticle synthesis, Characterization, Wound healing activity, Hematology, Histology, Liver and kidney function test.

(c) 2018 The Authors. Published by Innovare Academic Sciences Pvt Ltd. This is an open access article under the CC BY license (http://creativecommons. org/licenses/by/4. 0/) DOI: http://dx.doi.org/10.22159/ajpcr.2018.v11i3.23531

\section{INTRODUCTION}

Nanotechnology is providing its great contribution in the routine lives of human beings [1-3]. Nanoparticles below $100 \mathrm{~nm}$ are reported to have unique characteristic properties, i.e. they have high surface-tovolume ratio [4,5]. Various methods are available for synthesizing nanoparticles [6,7]; among them, the commercial methods of physical [8] and chemical methods [9,10] are the common one. But certainly, they have some disadvantages as in the physical method of nanoparticle synthesis, astronomically immense and costly instruments are required which exploit large area for the synthesizing purpose, and the process of aerosols are hazardous to the environment [11-13]. The chemical synthesis of nanoparticles employs utilization of rigorous and toxic chemicals withal this method which requires a highly stringent protocol $[14,15]$. The nanoparticles thus synthesized by such methods are toxic to the environment and ultimately result in environmental degradation [16]. The biological method of nanoparticle synthesis is an alternative approach for these conventional methods, as the method is quite non-hazardous, frugal, facilely scaled up, and does not require multiple steps $[17,18]$. Plants, microorganisms, fungi, bacteria, yeast, actinomycetes, etc., are some of the components in the biological system [19], which are designated for synthesizing metal nanoparticles [20-22]. The phytoconstituents available in the plant extract (P.E) are kenned to have the capacity of synthesizing metal nanoparticles and are withal utilized as capping agent [23-28]. Thus, the plant metabolites act both as reducing and capping agents for metal nanoparticles [29-32]. The most consequential constituents present in the P.E responsible for nanoparticle synthesis and their capping are flavonoids, terpenoids, and phenols [33]. Metal nanoparticles are reported to have good antibacterial activity [34-36]. Few antibiotics are available in the market, but the development of resistance by pathogens against particular antibiotic is a common process, thus a high dose of such antibiotic is required [37-41]. Wound healing is a very prevalent phenomenon, but in diabetic wound, the healing process gets delayed due to lowering of several physiological processes [42,43], which ultimately leads to infectious wounds and then delayed healing [44-47]. Hence, in this study, an ecofriendly approach for biosynthesizing metal nanoparticles has been applied, which is low cost, facilely scaled up, feasible, and may act as better therapeutic agent for wound management

\section{MATERIALS AND METHODS}

Materials

Magnetic bead, conical flask, test tubes, scissors, surgical blade for surgical process, transparent polythene sheet, permanent marker for measurement of wound area, graph paper, and One-touch glucometer (ACCU-CHEK Sensor Comfort) of Roche Diagnostics were purchased. The required chemical such as silver nitrate metal salt was purchased from Fisher-Scientific. Streptozotocin (STZ) was purchased from Sigma- Aldrich Co., USA. Simple ointment base. Anesthetic Ether, normal saline, and the reference drug used was povidone-iodine. 


\section{Methods}

\section{Collection of leaves and extract preparation}

Fresh leaves of Syzygium cumini were collected from the campus of Botanical garden, Jiwaji University, Gwalior. The leaves were washed exhaustively by distilled water and then dried on filter paper. The leaves were then grinded by denotes of motor pistal followed by filtration so as to abstract the solid waste. Solvent extraction [48-50] of leaves was then done using 30\% ethanol and water. The extract was then stored at $4^{\circ} \mathrm{C}$ for further use [51-53].

\section{Synthesis of silver nanoparticles and characterization}

$0.01 \mathrm{M}$ of $\mathrm{AgNO}_{3}$ salt solution was taken in Erlenmeyer flask. The reduction of nanoparticles was done using $S$. cumini leaf extract, whereas chemical synthesis of the nanoparticles was done using $\mathrm{NaBH}_{4}$ where PVP was used as a capping agent. The reducing agents were integrated drop wise until the colloidal suspension appears. The solution was then allowed to mix on a magnetic stirrer at room temperature, until the color change appears. The suspension was then allowed for centrifugation, and then pellets were collected, washed, and then dried [54]. The sample was then stored for further use. The synthesized nanoparticles were then allowed to go through various characterization processes so as to understand the size and shape distribution. Ultraviolet-visible (UV-VIS) spectroscopy, Fourier transform infrared spectroscopy (FTIR), scanning electron microscopy (SEM), transmission electron microscopy (TEM), etc., are some of the characterization techniques that were opted for the characterization process [55].

In vivo study

The present work was performed in compliance with the Germane laws and institutional guidelines and the study was approved by the Animal Ethical Committee of Jiwaji University. All the thirty male Wistar rats of weight approximately 250-300 g were obtained from the Defence Research and Development Establishment, Gwalior, India.

Acclimatization of all the animals to laboratory conditions was done $\left(25-30^{\circ} \mathrm{C}\right.$ and at $45-55 \%$ relative sultriness for $12 \mathrm{~h}$, each of light and dark cycle) prior to experiment [56]. The effective concentration of nanoparticles was chosen for in vivo study. The animals were then divided into five groups, which were treated with biosynthesized silver nanoparticles (Group 1), chemically synthesized silver nanoparticles (Group 2), presubsisting drug povidone-iodine (Group 3), diabetic controls (DC) that were left untreated (Group 4), and normal controls (NC) that were left untreated (Group 5).

Diabetes was induced in overnight-fasted rats by single intraperitoneal injection of freshly prepared STZ (45 mg/kg body weight) in $0.1 \mathrm{M}$ citrate buffer, $\mathrm{pH} 4.5$ [57]. Hyperglycemia was corroborated by checking the blood glucose (by ACCU-CHEK sensor glucometer) after $48 \mathrm{~h}$ of STZ injection. Rats exhibiting blood glucose $>200 \mathrm{mg} / \mathrm{dl}$ at $48 \mathrm{~h}$ after STZ injection were used for the experiments and regular monitoring of blood glucose level was done throughout the study.

Dorsal surgery was done after giving anesthesia. The animals were anesthetized with diethyl ether and $2.0 \times 2.0 \mathrm{~cm}^{2}$ excision wound was developed. The wound healing parameters that were estimated during in vivo assessment include area quantification which was done by utilizing a Ruler method [58]. Data obtained from quantification of the area were analyzed by one-way ANOVA, where values are statistically significant at $\mathrm{p}<0.05\left({ }^{*}\right),{ }^{* *} \mathrm{p}<0.01$. Monitoring of all parameters such as biochemical (liver and kidney function), hematological, and skin histology parameters was done.

Kidney and liver functions were estimated in blood plasma by utilizing standard kits $[59,60]$. Automated blood analyzer was used to evaluate various hematological parameters such as hematocrit (Hct), platelet (PLT) count, hemoglobin concentration $(\mathrm{Hb})$, total erythrocyte count (red blood cell [RBC]), and total leukocyte count (white blood cell [WBC]).

For skin histology, each specimen (skin tissue) was cut with a blade from all groups. The cut piece was fixed with $10 \%$ formalin and embedded in paraffin. The skin of the wound was cut in $5 \mu \mathrm{m}$ and stained with hematoxylin and eosin and then visualized under light microscopy to determine various parameters.

\section{RESULTS AND DISCUSSION}

Characterization of metal nanoparticles

Visible change in the color was observed in the metal salt solution from white foggy to brown which denotes the formation of nanoparticles. The change in the color of the solution is due to change in the surface plasmon resonance of the particles.

\section{UV-VIS spectroscopy}

The UV-VIS spectroscopy showed SPR spectrum absorbance at $419 \mathrm{~nm}$ of silver nanoparticles synthesized by biological route (Fig. 1) and $409 \mathrm{~nm}$ of silver nanoparticles synthesized by chemical route (Fig. 2), which is already recorded for silver nanoparticles. The position of the spectra may shift depending on the size and shape of the synthesized nanoparticles.

\section{FTIR analysis}

The FTIR results obtained from biosynthesized silver nanoparticles give characteristic peaks. The peak at $3429.22 / \mathrm{cm}, 2734.24 / \mathrm{cm}$, $1762.26 / \mathrm{cm}, 1655.25 / \mathrm{cm}, 824.00 / \mathrm{cm}$, and $800 / \mathrm{cm}$, which corresponds to the vibration, stretching, and bending characteristics of the chemical functional group, presents within the sample. The various peaks obtained refer to $\mathrm{O}-\mathrm{H}$ stretch of phenols, $\mathrm{C}$-H stretch of aldehydes, $\mathrm{C}=\mathrm{O}$ stretch of carboxylic acids, $\mathrm{N}-\mathrm{H}$ bend of primary amines, $\mathrm{C}-\mathrm{CH}$ bending of aromatics, and $\mathrm{C}-\mathrm{Cl}$ stretching vibration of alkyl halides. The presence of various chemical functional groups suggests that probably the phytochemical utilized for reduction purpose during synthesis may be acting as a capping agent for nanoparticles (Fig. 3).

The FTIR results obtained from chemically synthesized silver nanoparticles give characteristic peaks. The peak at $2929.29 / \mathrm{cm}$, $1550.24 / \mathrm{cm}, 1418.24 / \mathrm{cm}, 1156.28 / \mathrm{cm}, 1023.28 / \mathrm{cm}, 951.30 / \mathrm{cm}$, $755.31 / \mathrm{cm}, 688.29 / \mathrm{cm}$, and $615.31 / \mathrm{cm}$, which corresponds to the vibration, stretching, and bending characteristics of the chemical functional group, presents within the sample. The various peaks thus obtained refer to 0 -H stretching vibrations, $\mathrm{C}-\mathrm{H}$ asymmetric stretching vibrations, $\mathrm{C}=\mathrm{O}$ stretching vibration, $\mathrm{C}-\mathrm{N}$ stretching vibrations, and $\mathrm{CH} 2$ bending vibrations. The presence of various chemical functional groups suggests that the chemical utilized for reduction purpose during synthesis may be acting as a capping agent for nanoparticles (Fig. 4).

\section{TEM analysis}

TEM results of biosynthesized silver nanoparticles showed that the nanoparticles were ranging from 16 to $45 \mathrm{~nm}$, with an average size of $42.40 \mathrm{~nm}$. Most of the silver nanoparticles were roughly circular with smooth edges. The phytochemical constituents in the $S$. cumini leaves such as tannins, phenols, terpenoids, proteins, saponins, and flavonoids may act as reducing agents during the synthesis of silver nanoparticles (Fig. 5).

TEM analysis of chemically synthesized silver nanoparticles showed that the silver nanoparticles were ranging from 15 to $42 \mathrm{~nm}$, with an average size of $38.1 \mathrm{~nm}$ (Fig. 6).

\section{SEM analysis}

SEM analysis limpidly depicts that the nanoparticles synthesized by both biological and chemical routes were of spherical and ellipsoidal shapes (Figs. 7 and 8).

\section{In vivo study}

During 16 days of topical therapy of nanoparticles on wounds, the glucose level in STZ-induced diabetic rats was monitored regularly throughout the therapy. 


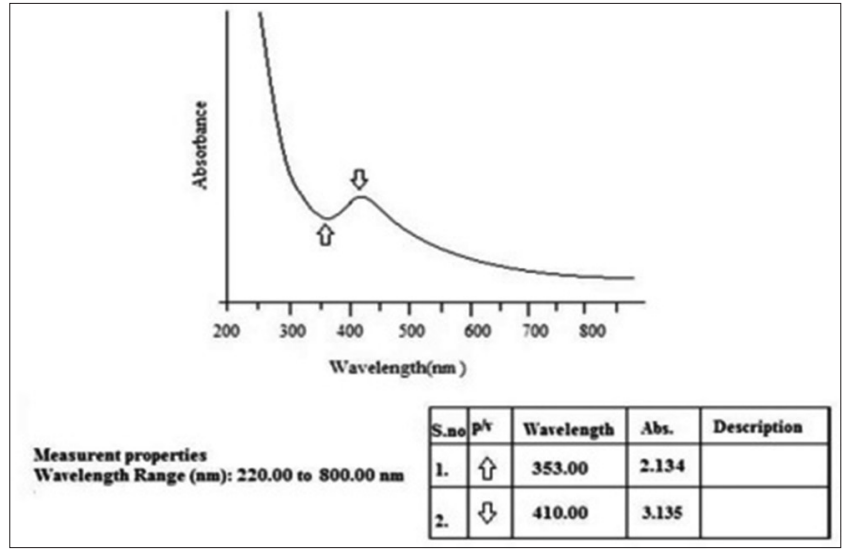

Fig. 1: Ultraviolet-visible analysis of biofabricated silver nanoparticles

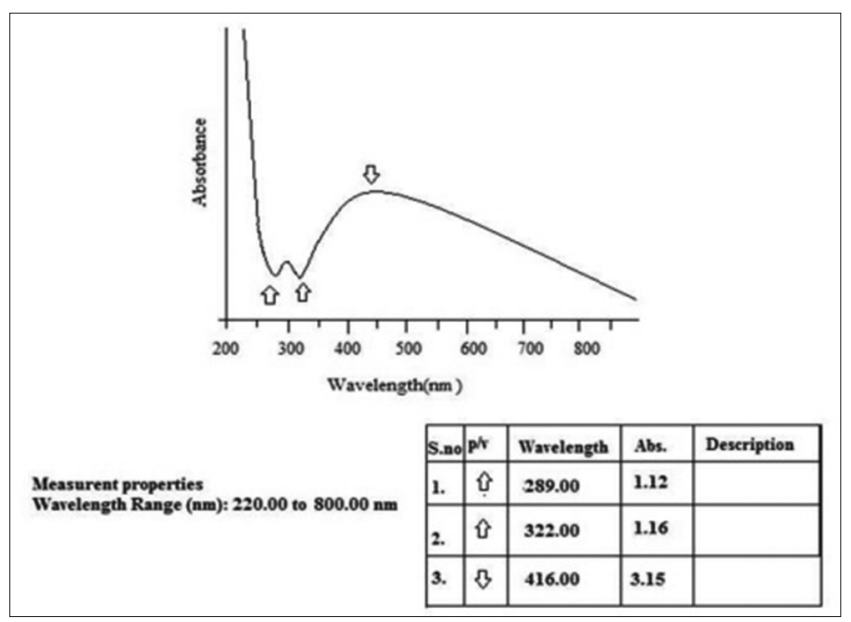

Fig. 2: Ultraviolet-visible analysis of chemically synthesized silver nanoparticles

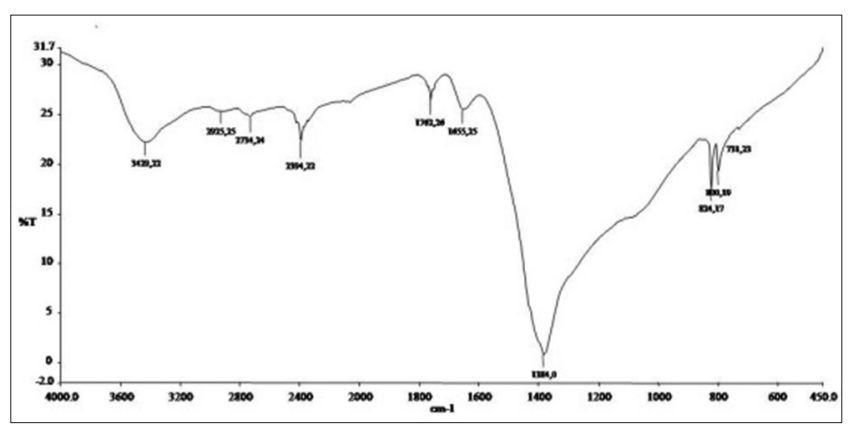

Fig. 3: Fourier transform infrared analysis of biofabricated silver nanoparticles

Evaluation of change in area and age of wound during therapy

During 16 days of topical therapy of different metal nanoparticle formulation on wounds of diabetic Wistar rats, the wound area reduction that took place is shown in Table 1.

\section{Evaluation of wound contraction and epithelialization}

The rate of rejuvenating was calculated and expressed as percentage contraction. The changes in the percentage of wound contraction and epithelialization are shown in Table 2.

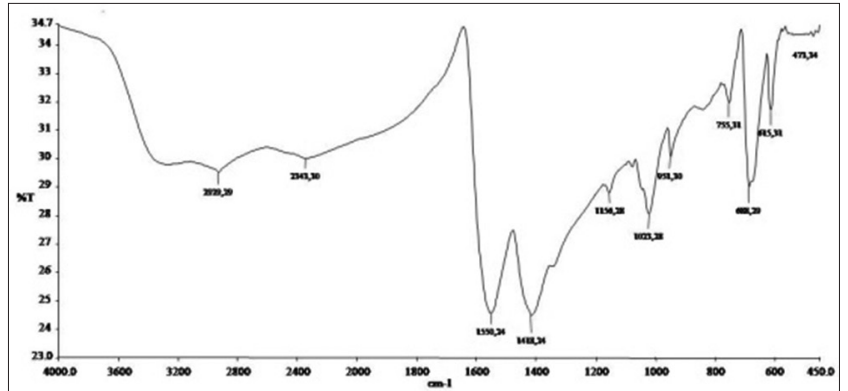

Fig. 4: Fourier transform infrared analysis of chemically synthesized silver nanoparticles

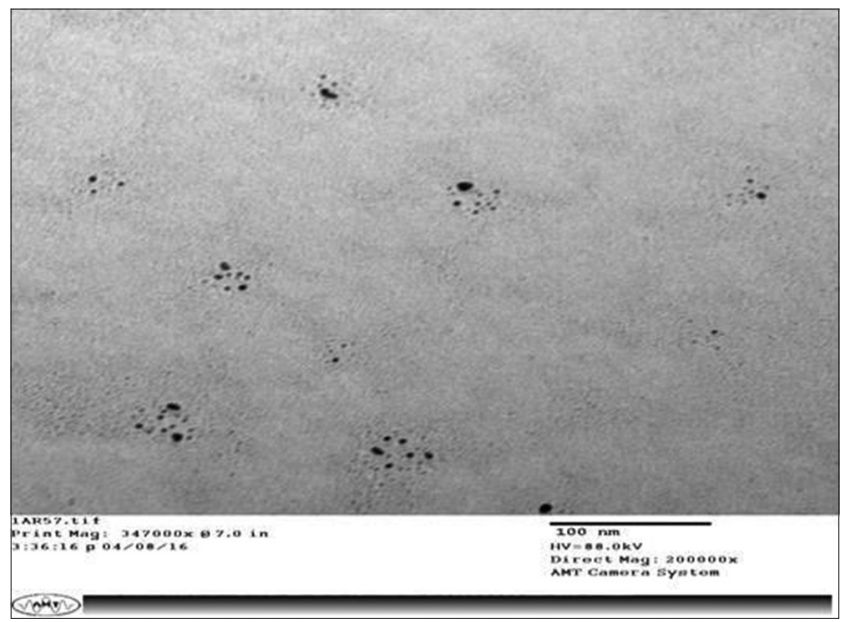

Fig. 5: Transmission electron microscopy analysis of biofabricated silver nanoparticles

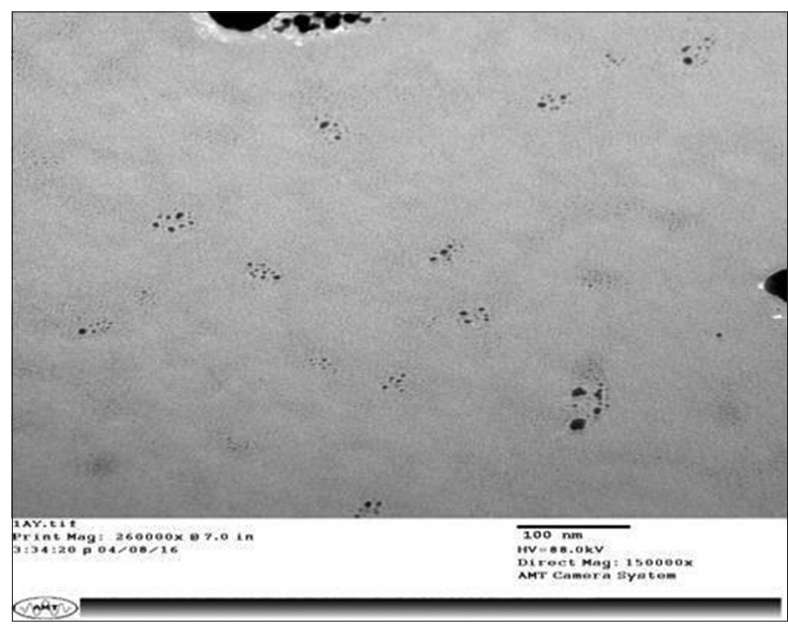

Fig. 6: Transmission electron microscopy analysis of chemically synthesized silver nanoparticles

Biochemical parameters

Urea level, uric acid level, and creatinine level (kidney function test)

During 16 days of topical therapy of nanoparticles on wounds, kidney function test done afore and after therapy revealed that the highest elevation of urea, uric acid, and creatinine level among all groups was optically discerned in Group 3. The changes in the urea level, uric acid level, and creatinine level are shown in Table 3. 
Table 1: Percentage reduction in wound area after therapy along with complete healing of wound (in days)

\begin{tabular}{|c|c|c|c|}
\hline Groups & Percentage reduction in wound area after therapy (in \%) & Complete healing (in days) & Significance level \\
\hline Group 1 & $96.09 \%$ reduction & $15^{\text {th }}$ day & $\mathrm{p}=0.011^{*}$ \\
\hline Group 2 & $97.7 \%$ reduction & $14^{\text {th }}$ day & $\mathrm{p}=0.002^{* *}$ \\
\hline Group 3 & $64.28 \%$ reduction & No complete healing & $\mathrm{p}=0.04^{*}$ \\
\hline Group 4 & $37.5 \%$ reduction & No complete healing & Non-significant \\
\hline Group 5 & $97.5 \%$ reduction & $13^{\text {th }}$ day & $\mathrm{p}=0.016^{* *}$ \\
\hline
\end{tabular}

Data were analyzed by one-way ANOVA. Values are statistically significant at $\mathrm{P}<0.05^{*},{ }^{* *} \mathrm{p}<0.01$. ANOVA: Analysis of variance

Table 2: Percentage of epithelialization level and wound contraction

\begin{tabular}{llllll}
\hline Groups & \multicolumn{2}{l}{ Percentage of wound contraction } & & \multicolumn{2}{l}{ Percentage of epithelialization level } \\
\cline { 2 - 3 } \cline { 5 - 6 } & Before therapy (on $\mathbf{4}^{\text {th }}$ day) & After therapy (on $\left.\mathbf{1 6}^{\text {th }} \mathbf{d a y}\right)$ & & Before therapy (on $\mathbf{4}^{\text {th }}$ day) & After therapy (on 16 $\mathbf{1 6}^{\text {th }}$ day) \\
\hline Group 1 & $21.10 \%$ & $94.11 \% *(\mathrm{p}<0.05)$ & & $19.8 \%$ & $92.1 \% \%^{*}(\mathrm{p}<0.05)$ \\
Group 2 & $29.14 \%$ & $93.10 \% \%^{*}(\mathrm{p}<0.05)$ & & 22.35 & $96.6 \% \%^{*}(\mathrm{p}<0.05)$ \\
Group 3 & $16.08 \%$ & $64.08 \%(\mathrm{p}>0.05)$ & & $13.2 \%$ & $73.2 \%(\mathrm{p}>0.05)$ \\
Group 4 & $25.01 \%$ & $37.08 \%(\mathrm{p}>0.05)$ & $22.1 \%$ & $45.4 \%(\mathrm{p}>0.05)$ \\
Group 5 & $36.18 \%$ & $97.42 \%(\mathrm{p}<0.05)$ & $28.6 \%$ & $97.7 \%(\mathrm{p}<0.01)$ \\
\hline
\end{tabular}

Data were analyzed by one-way ANOVA. Values are statistically significant at ${ }^{*} \mathrm{p}<0.05^{*},{ }^{* *} \mathrm{p}<0.01$. ANOVA: Analysis of variance

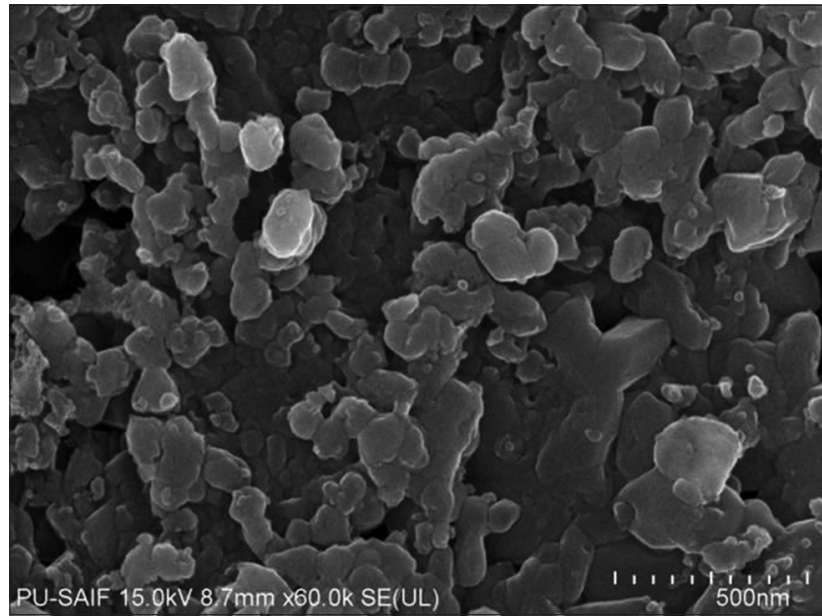

Fig. 7: Scanning electron microscopy analysis of biofabricated silver nanoparticles

Serum glutamate pyruvate transaminase (SGPT), serum glutamate oxaloacetate transaminase (SGOT), and bilirubin level (liver function test)

During 16 days of topical therapy of nanoparticles on wounds, liver function test done afore and after therapy revealed that the highest elevation in SGPT, SGOT, and creatinine was optically discerned in Group 3. The changes in the SGPT, SGOT, and bilirubin level are shown in Table 4.

Results obtained from liver and kidney function analysis have shown that chemically synthesized silver nanoparticles have enhanced wound rejuvenating activity but they withal have incremented toxicity level in liver and kidney. Hence, biologically synthesized silver nanoparticles can be utilized as an excellent alternative for treating impaired diabetic wounds because of their consequential wound rejuvenating activity with low toxicity level in liver and kidney.

\section{Hematological parameters}

Evaluation of changes in hematological parameters in various groups after completion of therapy is listed in Table 5 .

Previous studies have shown that the normal range of PLT count in laboratory rats is $680-120010^{3} / \mu \mathrm{L}$, Hct is $37.9-49.9 \%$, WBC count is $1.96-8.2510^{3} / \mu \mathrm{L}, \mathrm{RBC}$ count is $7.27-9.6510^{6} / \mu \mathrm{L}$, and hemoglobin is 13.7-17.6 g/dL. The results thus obtained have shown that the topical application of nanoparticles on wounds has no such effects or too much

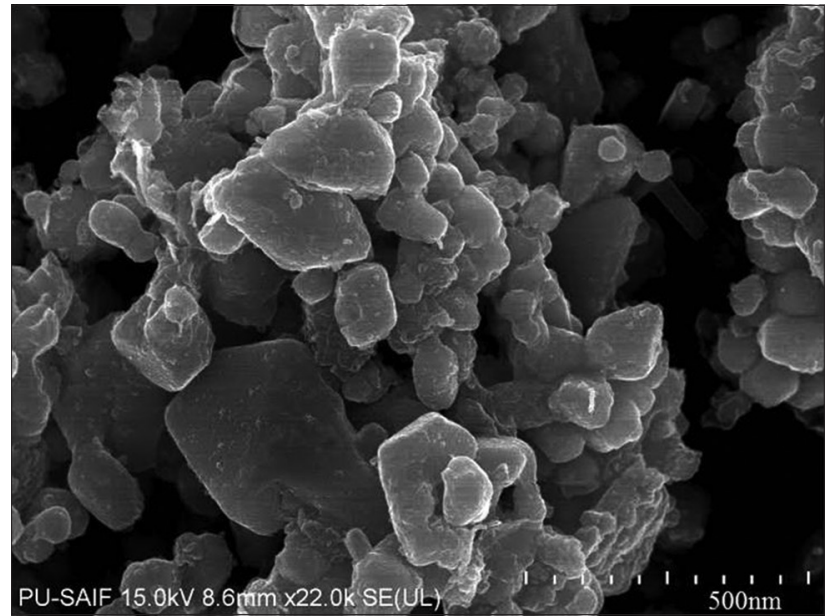

Fig. 8: Scanning electron microscopy analysis of chemically synthesized silver nanoparticles

variation from their normal range on hematological parameters such as Hct (\%), PLT count $\left(10^{3} / \mu \mathrm{L}\right)$, and $\mathrm{Hb}$ concentration $\mathrm{Hgb}(\mathrm{g} / \mathrm{dL})$, but there is a partial decline in RBC counts in Group 2. Also, there is a partial elevation in WBC counts in Groups 1, 3, and 4.

\section{Photography of wound at different time intervals}

In Group 1, i.e., biosynthesized silver nanoparticle-treated group, there is amended wound healing with increased rate of hairation along with reduced scar which can be optically discerned in Fig. 9.

Group 2, i.e., chemically synthesized silver nanoparticle-treated group during in vitro studies, has shown good antibacterial activity but has reduced wound healing activity in comparison to other nanotreated group which is clearly visually shown in Fig. 10.

Group 3, i.e. reference drug (povidone-iodine)-treated group does not get healed properly and showed delayed wound healing, along with marginal inflammation throughout the study, thus considered as non-paramount for wound therapy (Fig. 11).

Group 4, i.e., DC, showed no denotement of auto healing of wounds along with increased inflammation (Fig. 12).

Group 5, i.e., NC, showed auto healing along with paramount reduction of wound area (Fig. 13) 
Table 3: Changes in urea level, uric acid level, and creatinine level

\begin{tabular}{llll}
\hline Groups & Urea (mg/dl) & Uric acid (mg/dl) & Creatinine (mg/dl) \\
\hline Group 1 (biosynthesized silver nanoparticles) & $51 \pm 2.16$ & $3.9 \pm 0.6$ & $0.59 \pm 0.02$ \\
Group 2 (chemically synthesized silver nanoparticles) & $54.6 \pm 1.4$ & $5.2 \pm 0.1$ & $0.91 \pm 0.01$ \\
Group 3 (preexisting drug) & $47.9 \pm 0.6$ & $3.9 \pm 0.2$ & $0.72 \pm 0.07$ \\
Group 4 (diabetic control) & $48.3 \pm 2.5$ & $3.03 \pm 0.1$ & $0.45 \pm 0.04$ \\
Group 5 (normal control) & $34.6 \pm 1.7$ & $2.46 \pm 0.1$ & $0.42 \pm 0.02$ \\
\hline
\end{tabular}

Values are presented as mean \pm standard error

Table 4: Changes in SGPT level, SGOT level, and bilirubin level

\begin{tabular}{lll}
\hline Groups & SGPT (U/L) & SGOT (U/L) \\
\hline Group 1 (biosynthesized silver nanoparticles) & $49.8 \pm 1.3$ & $81.1 \pm 4.6$ \\
Group 2 (chemically synthesized silver nanoparticles) & $54.6 \pm 2.4$ & $88.8 \pm 4.6$ \\
Group 3 (preexisting drug) & $51.9 \pm 3.6$ & $82.3 \pm 5.6$ \\
Group 4 (diabetic control) & $52.8 \pm 2.4$ & $80.0 \pm 4.5$ \\
Group 5 (normal control) & $37.2 \pm 1.6$ & $0.92 \pm 0.1$ \\
\hline
\end{tabular}

Values are presented as mean \pm standard error. SGPT: Serum glutamate pyruvate transaminase, SGOT: Serum glutamate oxaloacetate transaminase

Table 5: Changes in hematological parameters of different groups

\begin{tabular}{|c|c|c|c|c|c|c|}
\hline $\begin{array}{l}\text { Total leukocytes } \\
\left(\mathrm{WBC} \times 10^{3} / \mathrm{mm}^{3}\right)\end{array}$ & $\begin{array}{l}\text { Total erythrocyte } \\
\text { count/RBC } \\
\left(10^{6} / \mu \mathrm{L}\right)\end{array}$ & $\begin{array}{l}\text { Hemoglobin concentration } \\
\text { (g/dl) }\end{array}$ & $\begin{array}{l}\text { Platelet count } \\
\left(10^{3} / \mu \mathrm{L}\right)\end{array}$ & $\begin{array}{l}\text { Hematocrit } \\
\text { (\%) }\end{array}$ & \multicolumn{2}{|c|}{ Hematological parameters } \\
\hline $9.6 \pm 0.3$ & $6.89 \pm 0.34$ & $10.35 \pm 0.96$ & $690.2 \pm 78.30$ & $36.26 \pm 3.12$ & Group 1 & roups \\
\hline $10.7 \pm 0.2$ & $6.36 \pm 0.09$ & $9.21 \pm 0.47$ & $765.2 \pm 82.32$ & $38.32 \pm 0.21$ & Group 2 & fvalues a \\
\hline $9.9 \pm 0.8$ & $5.82 \pm 0.93$ & $11.61 \pm 0.28$ & $672.8 \pm 67.65$ & $34.42 \pm 0.98$ & Group 3 & presented as \\
\hline $11.9 \pm 0.1$ & $6.23 \pm 0.69$ & $11.23 \pm 0.86$ & $679 \pm 48.22$ & $38.02 \pm 2.39$ & Group 4 & mean+SD) \\
\hline $5.9 \pm 0.9$ & $8.26 \pm 0.02$ & $14.20 \pm 0.91$ & $760 \pm 38.33$ & $43.67 \pm 2.01$ & Group 5 & \\
\hline
\end{tabular}

Values are presented as mean \pm SE. SE: Standard error

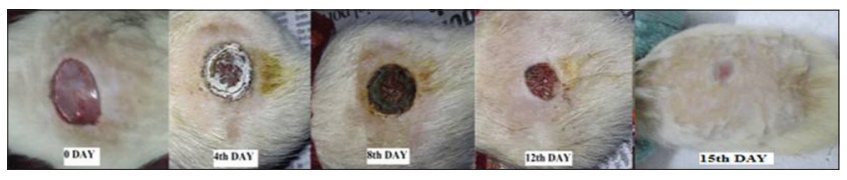

Fig. 10: Visible observation of wound healing in Group 2

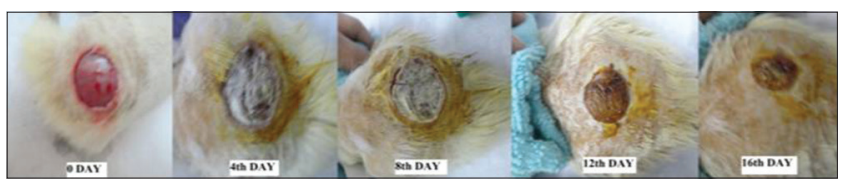

Fig. 11: Visible observation of wound healing in Group 3

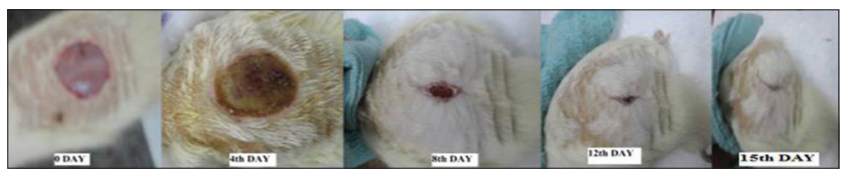

Fig. 9: Visible observation of wound healing in Group 1

\section{Histopathological parameters}

The results obtained from histological observation of skin tissue sections were divided into three grades; Grade 1: Low level, Grade 2: Moderate level, and Grade 3: Good level on the basis of availability of the various parameters chosen for histological observation of the skin tissue section, after therapy, as shown in Figs. $14-18^{[61]}$

Biosynthesized silver nanoparticle-treated group showed Grade 1: Collagen fibers, sebaceous glands, epithelialization; Grade 2: Hair follicles, melanocytes, neovascularization, granulation tissue; and Grade 3: Fibrosis, inflammatory cells showing lymphocytes and neutrophils, capillary, and venule.

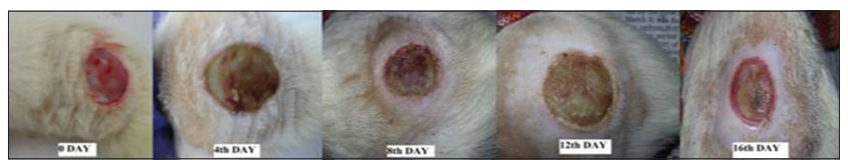

Fig. 12: Visible observation of wound healing in Group 4

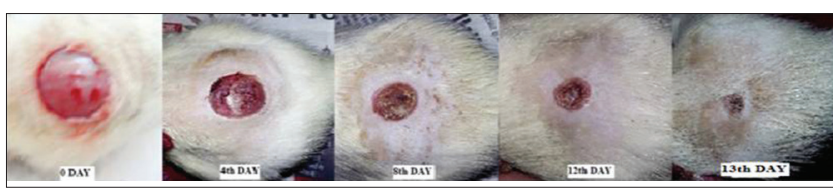

Fig. 13: Visible observation of wound healing in Group 5

Chemically synthesized silver nanoparticle-treated group showed Grade 1: Collagen fibers, melanocytes, epithelialization; Grade 2: Sebaceous glands, hair follicles, inflammatory cells showing lymphocytes and neutrophils, granulation tissue; and Grade 3: Fibrosis, neovascularization, capillary, and venule.

Reference drug povidone-iodine-treated group showed Grade 1: Collagen fibers, granulation tissue, epithelialization; Grade 2: Melanocytes and sebaceous glands; and Grade 3: Hair follicles, ducts, inflammatory cells showing lymphocytes and neutrophils, capillary, and venule, neovascularization, and fibrosis showing fibrocytes with elongated nucleus.

DC group showed Grade 1: Granulation tissue; Grade 2: Melanocytes, collagen fibers, and epithelialization; Grade 3: Hair follicles, ducts, sebaceous glands, inflammatory cells showing lymphocytes and neutrophils, capillary, and venule, neovascularization, fibrosis showing fibrocytes with elongated nucleus. 


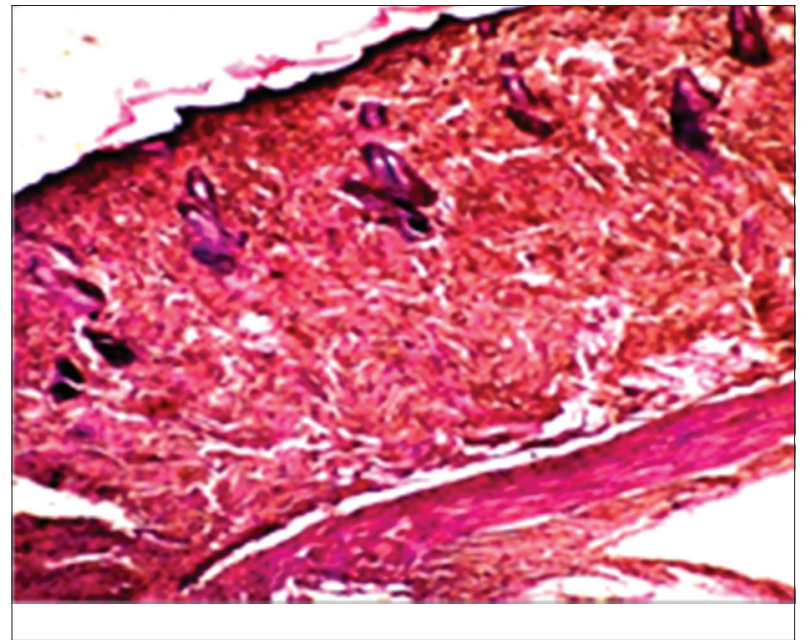

Fig. 14: Skin histology result of Group 1, i.e., biosynthesized silver nanoparticles

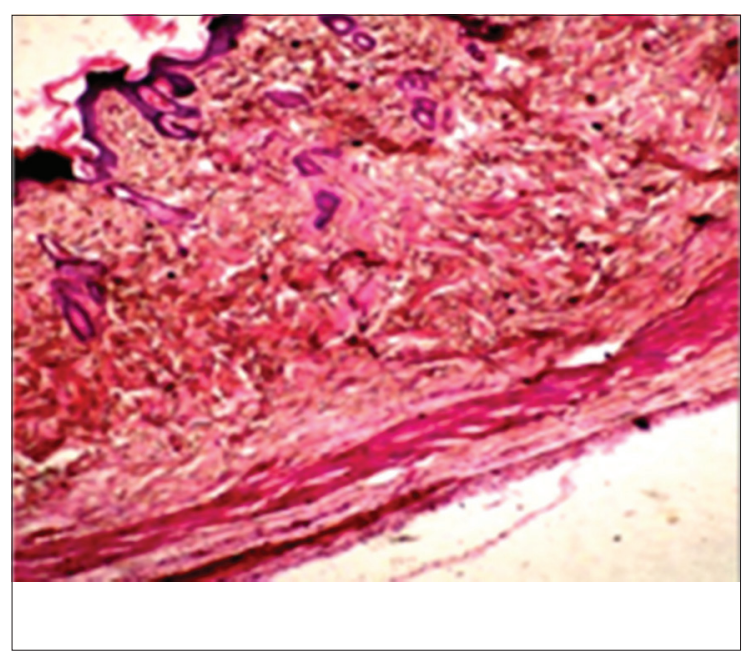

Fig. 15: Skin histology result of Group 2, i.e., chemically synthesized silver nanoparticles

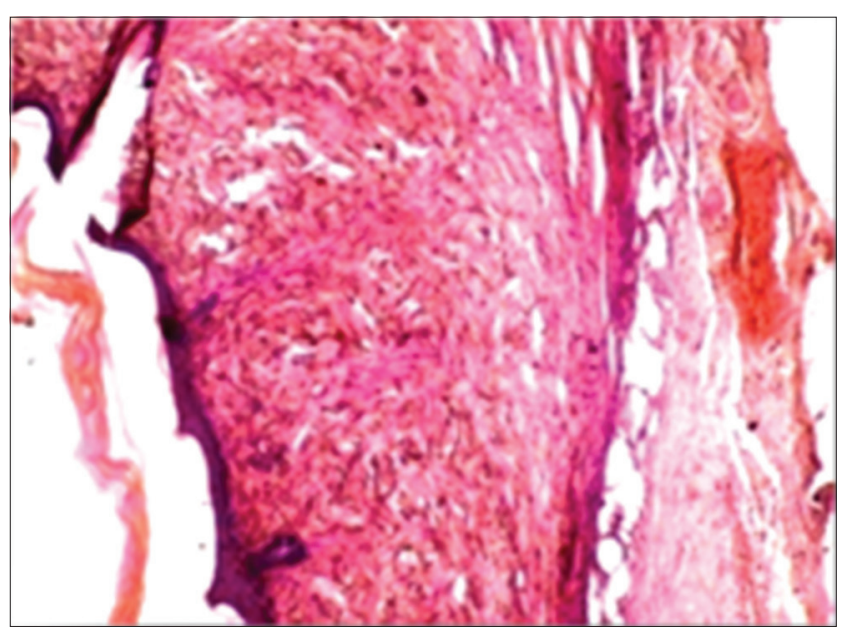

Fig. 16. Skin histology result of Group 3, i.e., reference drug povidone-iodine

NC group showed Grade 1: Hair follicles, ducts, sebaceous glands, granulation tissue, melanocytes, collagen fibers, epithelialization;

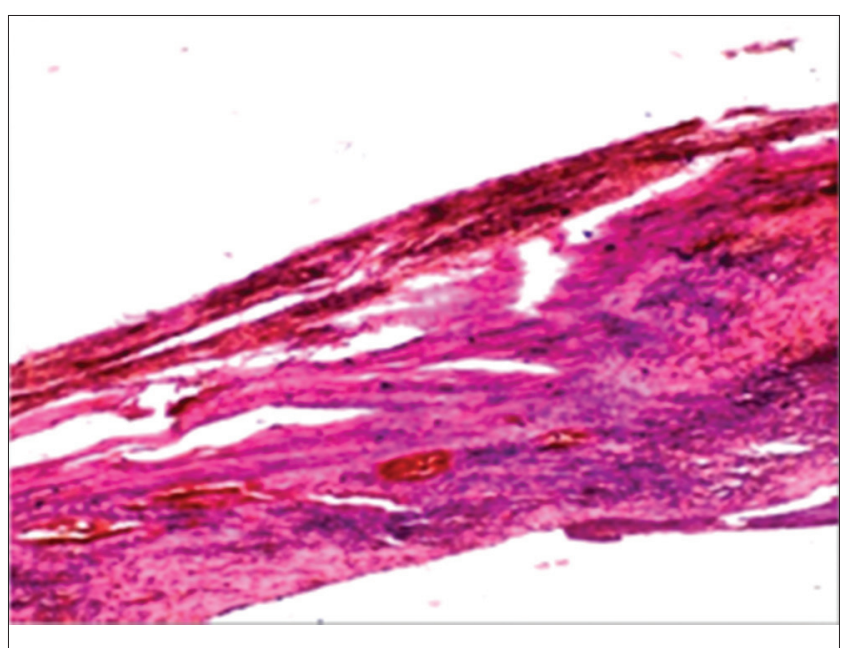

Fig. 17: Skin histology result of Group 4, i.e., diabetic control group

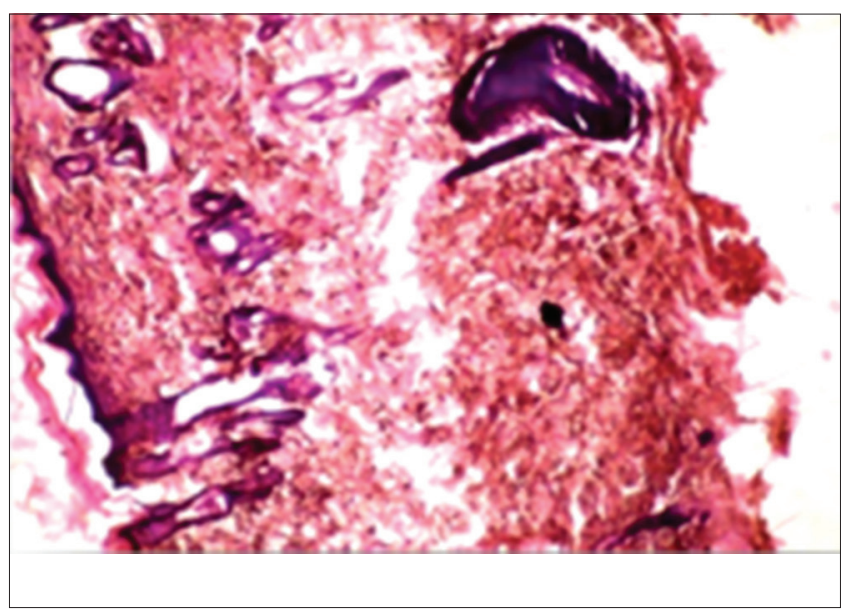

Fig. 18: Skin histology result of Group 5, i.e., normal control group

Grade 2: Capillary and venule, neovascularization, fibrosis showing fibrocytes with elongated nucleus; and Grade 3: Inflammatory cells showing lymphocytes and neutrophils.

\section{CONCLUSION}

The present study clearly depicts the efficiency of $S$. cumini leaf extract in the synthesis of silver nanoparticles. The P.E itself acts as reducing as well as capping agent, the synthesized particles are stable at room temperature and do not show agglomeration. The P.E used had proven to be an efficacious implement for synthesizing silver nanoparticles in the size range below $100 \mathrm{~nm}$ when analyzed by TEM and the shape of the particles is spherical/ellipsoidal which is clearly visually seen in the SEM analysis. The FTIR results obtained corroborate the presence of functional groups present within the phytochemical constituents of P.E. The synthesized nanoparticles showed potential wound healing potential in STZ-induced diabetic rats with low toxicity as compared to the chemically synthesized nanoparticles, with no such significant changes in hematological parameters, along with positive sign of wound healing as seen in skin histology results. Thus, it can be concluded that biosynthesized silver nanoparticles can be utilized as a better therapeutic implement for treating impaired diabetic wounds with increased wound healing efficacy, reduced scar, and health-care cost.

\section{ACKNOWLEDGMENT}

We would like to thank Dr. Ashok Kumar Chauhan, President, RBEF, parent organization of Amity University, Madhya Pradesh; Dr. Aseem 
Chauhan, Additional President, RBEF, and Chairman of AUMP Campus, Gwalior. We would also like to thank Lt. Gen. V. K. Sharma, AVSM (Retd.), Vice-chancellor of AUMP Gwalior Campus, Gwalior, India, for providing necessary facility and their valuable support and encouragement throughout the work.

\section{CONFLICT OF INTEREST}

The authors declare that they have no conflict of interest.

\section{REFERENCES}

1. Aithal PS. Nanotechnology innovations and business opportunities: A review. Int J Manag IT Eng 2016;6:182-204.

2. Raj S, Jose S, Sumod US, Sabitha M. Nanotechnology in cosmetics: Opportunities and challenges. J Pharm Bioallied Sci 2012;4:186-93.

3. Gajbhiye S, Sakharwade S. Silver nanoparticles in cosmetics. J Cosmet Dermatol Sci Appl 2016;6:48-53.

4. Schmidt CW. Nanotechnology-related environment, health, and safety research: Examining the national strategy. Environ Health Perspect 2009; 117:A158-61.

5. Alanazi FK, Radwan AA, Alsarra IA. Biopharmaceutical applications of nanogold. Saudi Pharm J 2010;18:179-93.

6. Brandl F, Bertrand N, Lima EM, Langer R. Nanoparticles with photoinduced precipitation for the extraction of pollutants from water and soil. Nat Commun 2015;6:7765.

7. Tran QH, Nguyen VQ, Anh-Tuan L. Ag nanoparticles: Synthesis, properties, toxicology, applications and perspectives. Adv Nat Sci Nanosci Nanotechnol 2013;4:033001.

8. Velusamy P, Kumar GV, Jeyanthi V, Das J, Pachaiappan R. Bioinspired green nanoparticles: Synthesis, mechanism, and antibacterial application. Toxicol Res 2016;32:95-102.

9. Iravani S, Korbekandi H, Mirmohammadi SV, Zolfaghari B. Synthesis of Ag nanoparticles: Chemical, physical and biological methods. Res Pharm Sci 2014;9:385-406.

10. Banerjee S, Loza K, Meyer-Zaika W, Prymak O, Epple M. Structural evolution of Ag nanoparticles during wet-chemical synthesis. Chem Mater 2014;26:951-7.

11. Rauwel P, Rauwel E, Ferdov S, Singh MP. Ag nanoparticles: Synthesis, properties, and applications. Adv Mater Sci Eng 2015;682749:9

12. Umer A, Naveed S, Muhammad NR, Rafique S. Selection of a suitable method for the synthesis of copper nanoparticles. NANO 2012;7:18.

13. Naseri N, Valizadeh H, Zakeri-Milani P. Solid lipid nanoparticles and nanostructured lipid carriers: Structure, preparation and application. Adv Pharm Bull 2015;5:305-13.

14. Jo JH, Singh P, Kim YJ, Wang C, Mathiyalagan R, Jin CG, et al. Pseudomonas deceptionensis DC5-mediated synthesis of extracellular Ag nanoparticles. Artif Cells Nanomed Biotechnol 2015;44:1576-81.

15. Malik P, Shankar R, Malik V, Sharma N, Mukherjee T. Green chemistry based benign routes for nanoparticle synthesis. J Nanopart 2014;27:14.

16. Imran Din M, Rani A. Recent advances in the synthesis and stabilization of nickel and nickel oxide nanoparticles: A Green adeptness. Int J Anal Chem 2016;2016:3512145.

17. Simonin M, Richaume A. Impact of engineered nanoparticles on the activity, abundance, and diversity of soil microbial communities: A review. Environ Sci Pollut Res Int 2015;22:13710-23.

18. Poulose S, Panda T, Nair PP, Theodore TT. Biosynthesis of Ag nanoparticles. J Nanosci Nanotechnol 2014;14:2038-49.

19. Athira R, Nisha AP, Kumuthakalavalli R. Mycosynthesis of silver nanoparticles: Characterization, antioxidant and anti-inflammatory activity from Pleurotus florida (Mont) Singer: A macro fungi. Asian J Pharm Clin Res 2017;10:186-91.

20. Kumar CM, Yugandhar P, Savithramma N. Biological synthesis of Ag nanoparticles from Adansonia digitata L. fruit pulp extract, characterization, and its antimicrobial properties. J Intercult Ethnopharmacol 2016;5:79-85.

21. Azizi S, Namvar F, Mahdavi M, Ahmad MB, Mohamad R. Biosynthesis of silver nanoparticles using brown marine macroalga, Sargassum muticum aqueous extract. Materials (Basel) 2013;6:5942-50.

22. Singh P, Kim YJ, Singh H, Wang C, Hwang KH, Farh ME, et al. Biosynthesis, characterization, and antimicrobial applications of $\mathrm{Ag}$ nanoparticles. Int J Nanomed 2015;10:2567-77.

23. Gurunathan S, Jeong JK, Han JW, Xi FZ, Park JH, Kim JH. Multidimensional effects of biologically synthesized Ag nanoparticles in Helicobacter pylori, Helicobacter felis, and human lung (L132) and lung carcinoma A549 cells. Nanoscale Res Lett 2015;10:35.
24. Ghaffari-Moghaddam M, Hadi-Dabanlou R, Khajeh M, Rakhshanipour M, Shameli K. Green synthesis of Ag nanoparticles using plant extracts. Korean J Chem Eng 2014;31:548-57.

25. Rao PV, Nallappan D, Madhavi K, Rahman S, Jun Wei L, Gan SH, et al. Phytochemicals and biogenic metallic nanoparticles as anticancer agents. Oxid Med Cell Longev 2016;2016:3685671.

26. Wang C, Mathiyalagan R, Kim YJ, Castro-Aceituno V, Singh P, Ahn S, et al. Rapid green synthesis of $\mathrm{Ag}$ and gold nanoparticles using Dendropanax morbifera leaf extract and their anticancer activities. Int J Nanomed 2016;11:3691-701.

27. Ghosh S, Nitnavare R, Dewle A, Tomar GB, Chippalkatti R, More P, et al. Novel platinum-palladium bimetallic nanoparticles synthesized by Dioscorea bulbifera: Anticancer and antioxidant activities. Int J Nanomed 2015;10:7477-90.

28. Banerjee P, Satapathy M, Mukhopahayay A, Das P. Leaf extract mediated green synthesis of $\mathrm{Ag}$ nanoparticles from widely available Indian plants: Synthesis, characterization, antimicrobial property and toxicity analysis. Bioresour Bioprocess 2014;1:3.

29. Noruzi M. Biosynthesis of gold nanoparticles using plant extracts. Bioprocess Biosyst Eng 2015;38:1-4

30. Niska K, Knap N, Kędzia A, Jaskiewicz M, Kamysz W, InkielewiczStepniak I. Capping agent-dependent toxicity and antimicrobial activity of $\mathrm{Ag}$ nanoparticles: An in vitro study. Concerns about potential application in dental practice. Int J Med Sci 2016;13:772-82.

31. Parlinska-Wojtan M, Kus-Liskiewicz M, Depciuch J, Sadik O. Green synthesis and antibacterial effects of aqueous colloidal solutions of silver nanoparticles using camomile terpenoids as a combined reducing and capping agent. Bioprocess Biosyst Eng 2016;39:1213-23.

32. Chung M, Inmyoung $\mathrm{P}$, Kim SH, Thiruvengadam $\mathrm{M}$, Govindasamy R. Plant-mediated synthesis of Ag nanoparticles: Their characteristic properties and therapeutic applications. Nanoscale Res Lett 2014;11:40.

33. Reddy NJ, Vali DN, Rani M, Rani S. Evaluation of antioxidant, antibacterial and cytotoxic effects of green synthesized $\mathrm{Ag}$ nanoparticles by Piper longum fruit. Mater Sci Eng C 2014;34:115-122.

34. Naghdi M, Taheran M, Brar SK, Verma M, Surampalli RY, Valero JR, et al. Green and energy-efficient methods for the production of metallic nanoparticles. Beilstein J Nanotechnol 2015;6:2354-76.

35. Singh R, Nawale L, Arkile M, Wadhwani S, Shedbalkar U, Chopade S, et al. Phytogenic Ag, gold, and bimetallic nanoparticles as novel antitubercular agents. Int J Nanomed 2016;11:1889-97.

36. Lahra MM. Surveillance of antibiotic resistance in Neisseria gonorrhoeae in the WHO western pacific and South East Asian regions. Commun Dis Intell Q Rep 2010;36:95-100.

37. Ventola CL. The antibiotic resistance crisis: Part 2: Management strategies and new agents. P T 2015;40:344-52.

38. Davies J, Davies D. Origins and evolution of antibiotic resistance. Microbiol Mol Biol Rev 2010;74:417-33

39. Roca I, Akova M, Baquero F, Carlet J, Cavaleri M, Coenen S, et al. The global threat of antimicrobial resistance: Science for intervention. New Microbes New Infect 2015;6:22-29.

40. Lin J, Nishino K, Roberts MC, Tolmasky M, Aminov RI, Zhang L, et al. Mechanisms of antibiotic resistance. Front Microbiol 2015;6:34.

41. David MZ, Mennella C, Mansour M, Boyle-Vavra S, Daum RS. Predominance of Methicillin-resistant Staphylococcus aureus among pathogens causing skin and soft tissue infections in a large urban jail: Risk factors and recurrence rates. J Clin Microbiol 2008;46:3222-7.

42. Surana YS, Ashok P, Rajendran R. Evaluation Of antidiabetic, hypolipidemic and antioxidant activity Of polyherbal formulation in streptozotocin-nicotinamide induced diabetes in rats. Int J Pharm Pharm Sci 2017;9:105-10.

43. Saad EA, Habib SA, Refai WA, Elfayoumy AA. Malondialdehyde, adiponectin, nitric oxide, $\mathrm{C}$-reactive protein, tumor necrosis factoralpha and insulin resistance relationships and interrelationships in Type 2 diabetes early stage. Is metformin alone adequate in this stage? Int J Pharm Pharm Sci 2017;9:176-81.

44. Frykberg RG, Banks J. Challenges in the treatment of chronic wounds. Adv Wound Care (New Rochelle) 2015;4:560-82.

45. Hurlow J, Couch K, Laforet K, Bolton L, Metcalf D, Bowler P, et al. Clinical biofilms: A Challenging frontier in wound care. Adv Wound Care (New Rochelle) 2015;4:295-301.

46. Rowan MP, Cancio LC, Elster EA, Burmeister DM, Rose LF, Natesan S, et al. Burn wound healing and treatment: Review and advancements. Crit Care 2015;19:243.

47. Tuttle MS. Association between microbial bioburden and healing outcomes in venous leg ulcers: A Review of the evidence. Adv Wound Care (New Rochelle) 2015;4:1-1. 
48. Ahmed S, Saifullah, Ahmad M, Swami BL, Ikram S. Green synthesis of Ag nanoparticles using Azadirachta indica aqueous leaf extract. J Radiat Res Appl Sci 2016;9:1-7.

49. Senguttuvan J, Paulsamy S, Karthika K. Phytochemical analysis and evaluation of leaf and root parts of the medicinal herb, Hypochaeris radicata L. For in vitro antioxidant activities. Asian Pac J Trop Biomed 2014;4:S359-67.

50. Joseph BS, Kumbhare PH, Kale MC. Preliminary phytochemical screening of selected medicinal plants. Int Res J Sci Eng 2013;1:55-62.

51. Jaradat N, Hussen F, Anas AA. Preliminary phytochemical screening, quantitative estimation of total flavonoids, total phenols and antioxidant activity of Ephedra alata. Decne. J Mater Environ Sci 2015;6:1771-8.

52. Bag G, Devi PG, Bhaigyabati TH. Assessment of total flavonoid content and antioxidant activity of methanolic rhizome extract of three Hedychium species of Manipur valley. Int J Pharm Sci Rev Res 2015;30:154-9

53. Skerget M, Kotnik P, Hadolin M, Hras AR, Simonic M, Knez Z. Phenols, proanthocyanidins, flavones and flavonols in some plant materials and their antioxidant activities. Food Chem 2015;89:191-8.

54. Shrivastava V, Chauhan PS, Tomar RS. A biomimetic approach for synthesis of Ag nanoparticles using Murraya paniculata Leaf extract with reference to antimicrobial activity. J Pharm Sci Res 2016;8:247-50.

55. Heera $P$, Shanmugam S. Nanoparticle characterization and application: An overview. Int J Curr Microbiol App Sci 2015;4:379-86.

56. King AJ. The use of animal models in diabetes research. Br J Pharma 2012;166:877-94.

57. Furman BL. Streptozotocin-induced diabetic models in mice and rats. Curr Protoc Pharmacol 2015;70:5.47.1-20.

58. Shah AJ, Wollak C, Shah JB. Wound measurement techniques: Comparing the use of ruler method, 2D imaging and 3D scanner. J Am Coll Clin Wound Spec 2013;5:52-7.

59. Durán N, Nakazato G, Seabra AB. Antimicrobial activity of biogenic $\mathrm{Ag}$ nanoparticles, and $\mathrm{Ag}$ chloride nanoparticles: An overview and comments. Appl Microbiol Biotechnol 2016;100:6555-70

60. Bhatia D, Mittal A, Malik DK. Antimicrobial activity of PVP coated Ag nanoparticles synthesized by Lysinibacillus varians. Biotechnology 2016;6:196

61. Kiani FA, Kachiwal AB, Shah MG, Khan MS, Lochi GM, Manan A, et al. Histological characterization of wound healing of flank verses midline ovariohysterectomy in different age groups of cats. J Clin Pathol Forensic Med 2014;5:6-16. 